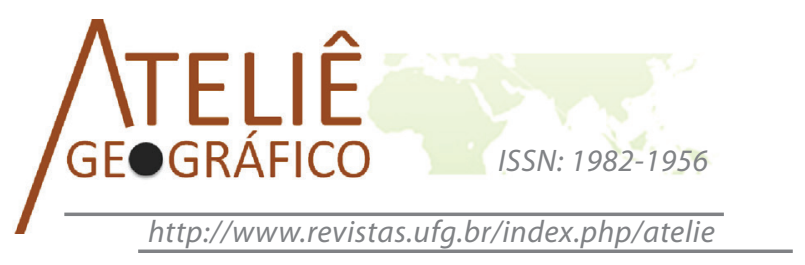

\title{
Escala intraurbana e produção do espaço em Senador Canedo (GO)
}

\author{
Intra-urban scale and the production of space in the \\ municipality of Senador Canedo (State of Goiás, Brazil)
}

\section{Escala intraurbana y espacio de producción en \\ Senador Canedo $(G O)$}

\author{
Leandro Oliveira Lima
}

Universidade Estadual de Goiás - Campus Goiás.

leandro_oliveira_lima@hotmail.com

\begin{abstract}
Resumo
A escala intraurbana tem sido uma ferramenta bastante utilizada em Geografia na compreensão dos processos de produção do espaço. No Brasil, dado o peso e a importância dos processos de urbanização e metropolização tal categoria delineou uma serie de apontamentos que são utilizados nos mais diversos ambientes acadêmicos e de gestão urbana. Este texto encaixa-se nesse preâmbulo e avalia a importância da escala intraurbana para a compreensão do processo de produção integrada do espaço urbano em ambientes metropolitanos, com avaliação mais detida sobre o município de Senador Canedo, na Região Metropolitana de Goiânia (RMG). Metodologicamente o texto contou com revisão bibliográfica, pesquisa de campo e mapeamento, subsidiando a reconstituição do processo de fragmentação e integração do tecido urbano de Senador Canedo à RMG.
\end{abstract}

Palavras-chave: intraurbano. Senador Canedo. RMG. produção do espaço.

\begin{abstract}
The intra-urban scale has been a tool broadly used in the field of Geography in the comprehension of the processes of production of space. In Brazil, given the weight and the importance of the processes of urbanization and metropolization, the intraurban scale delineated several notes used in several academic and urban management environments. This article aims to fit in this outset and evaluates the importance of the intra-urban scale for the comprehension of the process of production integrated of the urban space in metropolitan environments, focusing the evaluation over the municipality of Senador Canedo, in the Metropolitan Region of Goiania, state of
\end{abstract}


Goias, Brazil. Methodologically the text counted with bibliographic review, field research and mapping, supporting the reconstitution of the process of fragmentation and integration of the urban mesh of the municipality of Senador Canedo to the Metropolitan Region of Goiania

Keywords: intra-urban. Senador Canedo. RMG. Production of space.

\begin{abstract}
Resumen
La escala intra-urbana es una herramienta ampliamente utilizada en la Geografía en la comprensión de los procesos de producción del espacio. En Brasil, por su importancia en los procesos de urbanización y metrópolización como categoría esbozó una serie de notas que fueron y todavía se utilizan en diversos entornos académicos y la gestión urbana. Este texto se inscribe en este preámbulo y tiene como objetivo evaluar la importancia de la escala intra-urbana para la comprensión del proceso de producción del espacio urbano en entornos metropolitanos con evaluación más detallada del municipio de Senador Canedo, en la Région Métropolitaine de Goiânia (RMG) . Metodológicamente el artículo incluye revisión de la literatura, la investigación de campo y cartografía, el apoyo a la reconstrucción del proceso de fragmentación e integración del espacio urbano de Senador Canedo en RMG.
\end{abstract}

Palabras clave: intraurbano. Senador Canedo. RMG. producción del espacio.

\title{
Introdução
}

O processo de produção do espaço tem sido cada vez mais discutido seja em termos das políticas de gestão urbana ou mesmo nos frequentes debates da ciência geográfica. Considerando a centralidade do processo de produção do espaço o presente texto busca contribuir com a discussão da formação socioespacial do Município de Senador Canedo. O texto destaca também os diferentes processos que atuaram na configuração da estrutura fundiária e que, portanto, organizaram a produção do espaço contemporânea da porção leste da RMG.

A partir desses elementos, o artigo está dividido em três seções. A primeira versa sobre a importância e a singularidade da escala intraurbana no entendimento da Geografia. Sua contribuição reside na delimitação do processo histórico da produção do espaço. A segunda seção exemplifica como o município de Senador Canedo é visto como uma experiência de espaço intraurbano e suas peculiaridades na RMG. A última, está organizada a fim de explicitar como os processos históricos e espaciais se tornaram centrais na integração do espaço metropolitano. Esperamos que o artigo contribua com aprofundamento das leituras acerca das especificidades da produção do espaço urbano de Senador Canedo.

\section{O intraurbano como escala de análise}

Os estudos urbanos não estão saturados, principalmente aqueles que têm a escala regional e intraurbana como escala de análise. Há muito que avançar sobre o uso destas. Nesse entendimento, a geografia goiana vem se preocupando cada vez mais 
com os fenômenos alavancados na disputa por espaço em âmbito urbano. No caso da Geografia urbana goiana, a preocupação residiu desde a escala regional com os trabalhos de Barbosa et al. (2004) até a intraurbana como os desenvolvidos por Cavalcanti (2001; 2007; 2008), Paula (2003), Pinto (2009), Arrais (2006; 2012), Anjos (2009), Gomes (2007), e mais recentemente por Pinto (2014) em proposta teórica mais aprofundada sobre o papel das fronteiras em ambientes metropolitanos, e Lima (2014), em que pese a fragmentação fundiária para condomínios de chácaras na RMG.

A produção do espaço possui uma dinâmica interna que é orientada quase sempre de forma coordenada pelos atores hegemônicos. Analisar essa dinâmica é estudar o espaço intraurbano reconhecendo sua estruturação territorial ao longo de seu processo histórico. Mas qual é a importância do espaço intraurbano para os estudos urbanos? A resposta a essa pergunta pode ser feita assim: "reciprocamente, a nível intraurbano a cidade particular é o foco da atenção, e a análise é dirigida para a identificação e a explicação de padrões internos de uso do solo e suas interações” (CLARK, 1991, p. 22).

Para Villaça (1998), o intraurbano é importante, pois dá a dimensão exata das diferenças e contradições que se processam dentro da cidade. A fim de se ter um bom entendimento das questões do intraurbano, o autor menciona que é necessária a compreensão de quatro itens básicos: 1) a semântica; 2) a distinção entre espaço intraurbano e regional: 3) a especificidade do espaço intraurbano; 4) as confusões nas abordagens dos espaços intraurbanos e regionais. No semântico, o autor discute sobre a utilização do termo intraurbano, mesmo havendo redundância é necessário para qualificar de forma correta o objeto de estudo, pois usando a expressão espaço urbano pode-se entender por processo de urbanização, espaços regionais, nacionais, continentais e mesmo planetário.

Ainda segundo Villaça (1998), a escala intraurbana serve como análise no deslocamento do homem enquanto produtor desse espaço, ou seja, enquanto portador da mercadoria força de trabalho ou enquanto consumidor. Além disso, para Clark (1991), essa escala serve também na análise do desenvolvimento urbano em termos de centros intraurbanos e da expansão e declínio das áreas internas, refletindo as preferências de mudança locacional da indústria e a prosperidade diferencial da força de trabalho. Tal analise se relaciona ao segundo sentido atribuído por Vilaça (1998) em que pese a correlação imediata e distinta entre as forças que produzem o espaço intraurbano.

Os efeitos da metropolização goiana também sugerem uma análise integrada entre escalas. Nesse sentido, Senador Canedo, localizado na Região Metropolitana de Goiânia (ver figura 01) não pode ser analisado sem levar em conta a influência e a polarização da metrópole em sua malha urbana. Um exemplo disso foi a estruturação urbana da periferia leste às margens das GO 010 e GO 403, que expressou o processo de metropolização goianiense em Senador Canedo nas décadas de 1980 e 1990. Houve ainda, forte influência na migração, pressão demográfica por moradia e periferização, sobretudo nos últimos dois anos em virtude da política de duplicação das rodovias de acesso à capital. Esse processo também se efetivou no caso da GO 070 em Goianira, GO 060 em Trindade e BR 153 e GO 040 em Aparecida de Goiânia, conforme estudos feitos por Pinto (2009) e Anjos (2009) e GOs 010, 020 e 403 em Senador Canedo, segundo apontamentos recentes feitos por Lima (2014). Por isso mesmo a análise intraurbana, 
associada à narrativa metropolitana sugere peso significativo à explicação da morfologia urbana das cidades do entorno de Goiânia bem como seus padrões de conurbação aos elementos de integração da estrutura fundiária.

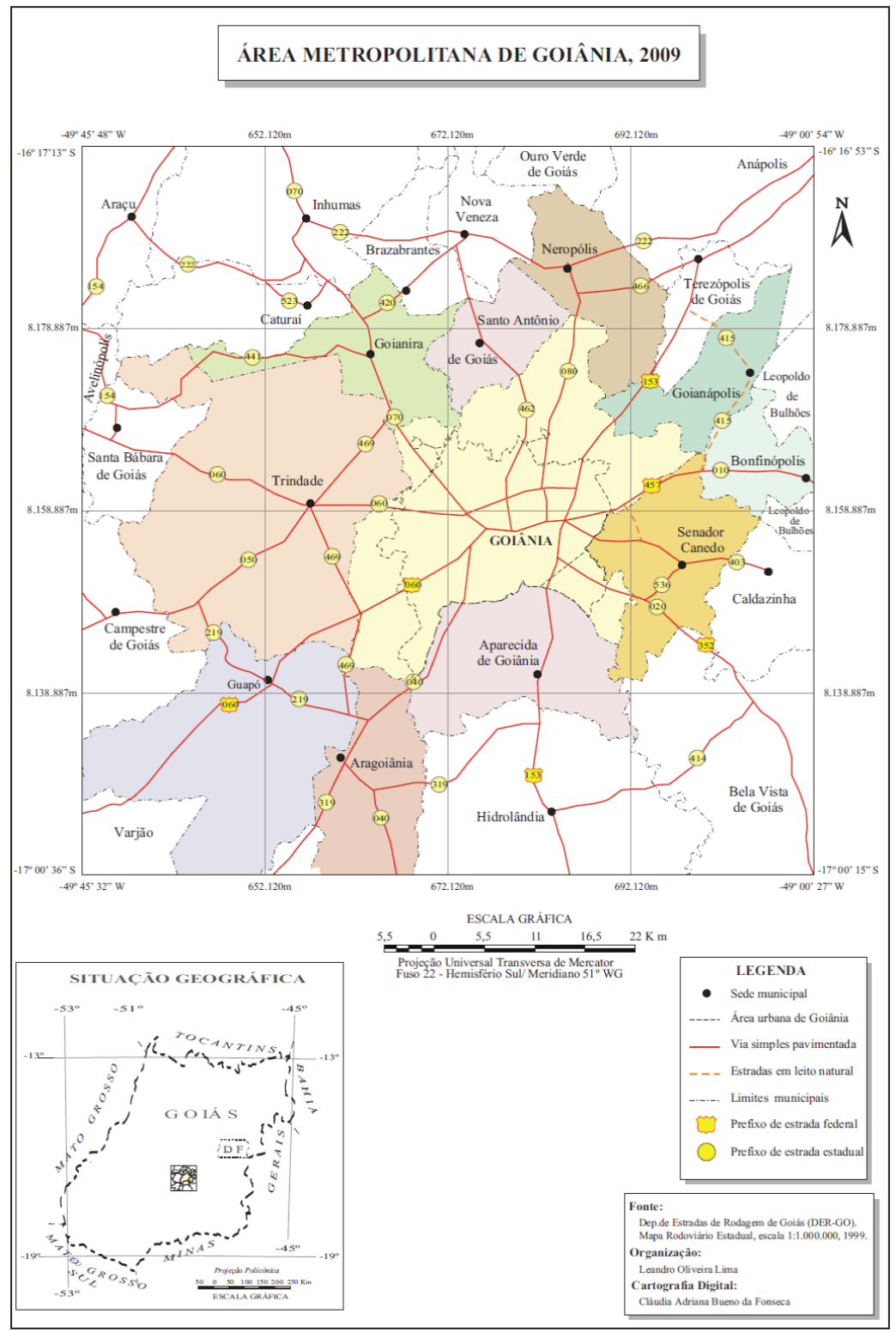

Figura 01: Área Metropolitana de Goiânia (2009) 
No caso específico de Senador Canedo, desde sua constituição em 1953 enquanto distrito, até 1989 com sua emancipação, a escala intraurbana privilegia uma compreensão detalhada da produção espacial do distrito para além da subordinação política, econômica e social que também se verificou nos outros municípios limítrofes à capital. Também permite compreender as novas dinâmicas que se estruturaram em Senador Canedo após a sua emancipação política - a atração de indústrias, serviços e pessoas (descentralização/ desconcentração industrial) - ao mesmo tempo em que o grau de integração-desintegração do município no contexto metropolitano bem como as características de fragmentação fundiária mostraram-se dependentes, haja vista Goiânia manter-se central em termos de oferta de mão-de-obra e serviços da RMG.

Outro ponto bastante peculiar de importância da análise intraurbana são os investimentos em infraestrutura na cidade. Sobre este tema, segundo Spósito (1998), ao nível intraurbano o poder público escolhe para seus investimentos em bens e serviços coletivos exatamente os lugares da cidade onde estão os segmentos populacionais de maior poder aquisitivo; ou que poderão ser vendidos e ocupados por estes segmentos, pois é preciso valorizar as áreas. Esta exposição tem importância teórica para a compreensão de Senador Canedo pois o munícipio tem peso significativo no ordenamento da produção do espaço na RMG. Há uma estreita ligação entre o poder político e o poder econômico e imobiliário na produção da porção leste da RMG alterando leis que favoreceram diretamente determinados atores políticos. Assim, se percebe as discrepâncias da função social do espaço no contexto metropolitano.

Em decorrência da produção desigual do espaço, os principais equipamentos urbanos disponíveis em ambientes metropolitanos interferem no deslocamento urbano tanto de matéria quanto do ser humano articulando, assim, no cotidiano, os fluxos de pessoas e mercadorias. Na compreensão da produção do espaço intraurbano é preciso entender também os processos que se desencadeiam (como por exemplo, a centralidade e a polinucleação) nas áreas centrais da cidade, destaca e atribui diferentes papéis funcionais na fragmentação dos espaços na periferia geográfica da metrópole.

A fragmentação dos espaços e dos usos no intraurbano constitui-se em um processo de estruturação territorial, que Spósito (2007) nomeou de reestruturação da cidade, através do qual denotam áreas de concentração e diversificação de comércio e serviços pertencentes a usuários de distintas classes sociais e que podem ser melhores avaliados pela análise intraurbana. Uma série de processos contemporâneos que se instauram nas metrópoles e, dentre esses, os ligados à produção do espaço espacial vinculados ao espraiamento do tecido urbano são assuntos estudados a partir dessa escala e podem ser consultados em Arrais (2013) e Lima (2014)

Para Villaça (1998), as especificidades do espaço intraurbano podem ser explicadas também pela localização dos objetos (equipamentos urbanos). Por isso mesmo, a produção do espaço, na maior parte das cidades brasileiras, implicou em fragmentação do tecido sociopolítico gerando segregação social e econômica, conforme atestou Souza (2000). Através de espaços residenciais para classes média e alta nos centros urbanos ao mesmo tempo em que expulsa a pobreza para a periferia, como aconteceu no caso da revitalização do "Bota Abaixo" implantado por Pereira Passos no Rio de Janeiro, organiza o espaço interno das cidades. Dai a importância de considerar o 
fator distância nos estudos sobre segregação socioespacial. Em Goiânia esse fenômeno ficou explícito na desapropriação do Parque Oeste Industrial, assunto que se tornou manchete nos principais jornais da cidade.

Nesse sentido, Bernardes (2000) demonstrou que mesmo Goiânia sendo capital planejada, ou seja, com política de controle sobre o espaço, isso não foi o suficiente para evitar as discrepâncias socioespaciais originadas no contexto da sua fundação até o seu crescimento dado pela intensa urbanização. Para Bernardes (2000, p. 173, grifos nossos)

\begin{abstract}
a ocupação do espaço não planejado ocorre concomitante à construção dos primeiros edifícios da cidade. Em que pesem a funcionalidade e as preocupações com o planejamento regional, com a preservação ecológica e com o zoneamento da cidade, não foi reservado um espaço no plano da cidade para aqueles que seriam os seus primeiros moradores, justamente os que vieram trabalhar na construção.
\end{abstract}

Dessa forma, a partir da periferia entendida como periferia social, as franjas da metrópole se configurou na medida que a urbanização do território, associado as altas taxas de migração de outras regiões do país, ampliavam a demanda de moradia aos atores de menor poder aquisitivo. Em outras palavras, a autora destaca o papel da não- localização referente à moradia das famílias trabalhadoras. Nesses termos, a periferização é um efeito ligado à ideia de localização, que implica em considerar determinados atores e interesses no processo de produção urbana. No discurso da urbanização/ metropolização a análise intraurbana exemplifica a realidade de Senador Canedo, assunto que será discutido a seguir.

\title{
Senador Canedo, espaço intraurbano na metrópole
}

Há duas premissas que nos instigam no estudo do espaço intraurbano na metrópole: a primeira é que, em virtude dos estudos que já foram feitos sobre Senador Canedo, observamos que a partir deles não visualizamos a cidade, pois os marcos regulatórios (leis) não são evidenciados pela literatura, induzindo o raciocínio a crer que trata-se de uma cidade sem ordenamento territorial. A segunda é que o espaço urbano inconsolidado - do ponto de vista do continuum urbano (ver figura 02), gerou explicações pontuais, pois consideraram partes que não explicam a totalidade do espaço urbano canedense, Tal fato, gerou certo tipo de leitura desintegrada da produção do espaço em Senador Canedo, e que inevitavelmente se estendeu à escala metropolitana.

Para analisarmos a produção do espaço canedense utilizaremos a regionalização administrativa como suporte. Porém, entendemos que os processos desencadeadores da configuração espacial que demandaram tal regionalização foram sociais e econômicos, expressão da segregação gestada e induzida pela metrópole, que configurou-se em tempos distintos e com interesses específicos. E, também, a partir da ação integrada dos atores do mercado imobiliário e das demandas por habitação registradas na RMG nas quatro últimas décadas. 


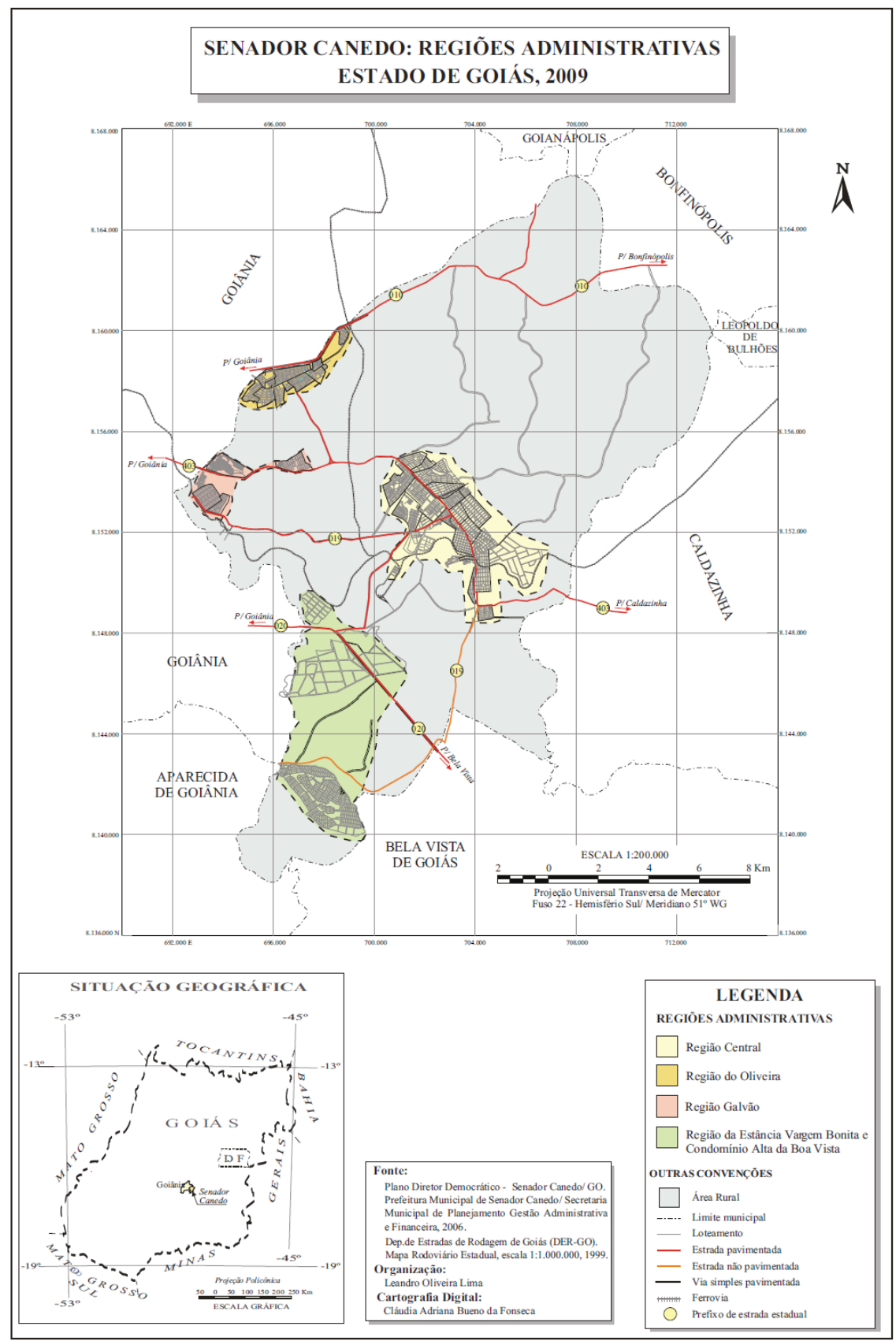

Figura 02: Senador Canedo: Regiões Administrativas (2009) 
O município encontra-se dividido em quatro regiões administrativas (ver quadro 01). Cada uma dessas regiões administrativas possui especificidades históricas e processos espaciais ocorrendo em tempos diferentes. A Região Central, dividida em quatro microrregiões, é o núcleo urbano mais antigo e é a sede do município. A Região da Vila Galvão, dividida em duas microrregiões, e a Região do Oliveira, dividia em três microrregiões, foram ocupadas efetivamente no final da década de 1980 e início dos anos 1990, sendo que são as duas regiões que apresentam íntima ligação com a expansão demográfica goianiense.

Quadro 01. Divisão Regional de Senador Canedo, Goiás (2014)

\begin{tabular}{|l|l|}
\hline Região & \multicolumn{1}{|c|}{ Bairros } \\
\hline \multirow{5}{*}{ Região Central } & $\begin{array}{l}\text { Conjunto Morada do Morro, Jardim Canedo I e II, Bairro Alvorada, } \\
\text { Bairro das Indústrias, Nova Goiânia, Setor Genoveva Resende, } \\
\text { Morada Nova, Residencial Boa Vista e Chácaras Alvorada, Jardim } \\
\text { Todos os Santos I,II e III, Conjunto Sabiá, Conjunto Uirapuru, } \\
\text { Residencial Anuar Auad, Setor Comercial, Recanto dos Sonhos, } \\
\text { Distrito Agroindustrial de Senador Canedo, Distrito Brasil Central, } \\
\text { Residencial Parque Vitória, Setor Central, Vila Santa Rosa I, II e III, } \\
\text { Vila Bonsucesso, Vale das Brisas, Chácaras Bom Sucesso, Vila São } \\
\text { Sebastião, Parque Industrial, Residencial Pedro Miranda, Setor Monte } \\
\text { Azul, Jardim Bouganville, Jardim Flamboyant, Chácaras Vargem } \\
\text { Bonita, Chácaras São Geraldo, Sítios Olhos d'água, Residencial } \\
\text { Laranjeiras, Residencial Aracy Amaral, }\end{array}$ \\
\hline Região Galvão & $\begin{array}{l}\text { Conjunto Valéria Perillo, Margarida Procópio, Vila São João I e II } \\
\text { e Condomínio Jardim Veneza, Vila Galvão, Condomínio Portugal, } \\
\text { Chácaras Retiro do Pescador, Residencial Marília e Chácaras Retiro }\end{array}$ \\
\hline Região Oliveiras & $\begin{array}{l}\text { Vila Matinha, Estrela do Sul, Morada do Sol, Jardim das Oliveiras, } \\
\text { Condomínio Tovolândia, Recanto das Oliveiras, Mansões Boa Sorte, } \\
\text { Jardim Liberdade, Residencial Rio Araguaia, Setor Castros, Parque } \\
\text { Alvorada I e II, Conjunto Residencial Flamboyant }\end{array}$ \\
\hline Região do Morumbi & $\begin{array}{l}\text { Estância Vargem Bonita e Condomínio Alto da Boa Vista, Alta Vista, } \\
\text { Condomínio Vila Colonial, Aurora das Mansões, Solar das Auroras, } \\
\text { Vila Retiro, Sítios de Recreio, Associação de Cabos e Soldados da } \\
\text { PM, Condomínio de Chácaras Vila Verde }\end{array}$ \\
\hline
\end{tabular}

Organizado pelo autor.

A Região do Morumbi, dividida em duas microrregiões, possui ocupações mais recentes (exceção da Vargem Bonita I) e se referem à chácaras e sítios de recreio, constituindo uma ocupação diferenciada tanto do ponto de vista do uso solo, como da ligação funcional, e também em termos do nível econômico dos atores que compõem a região.

Autores como Pinto (2009) e Anjos (2009) demonstraram em suas pesquisas que a supremacia goianiense "apagou" a história socioespacial de núcleos urbanos anteriores a criação de Goiânia em 1933, como foi o caso de Aparecida de Goiânia, Trindade, 
Campinas, Hidrolândia e Goianira. Em Senador Canedo a história socioespacial segue outra perspectiva.

O levantamento histórico feito por Moraes (2000) afirma que a origem do povoado é anterior à chegada da ferrovia, logo como local de pouso de boiadas na "região do Batata e do Bonsucesso". A institucionalização foi feita por Goiânia (lei n 239 de 1953) em terras principalmente do município de Bela Vista de Goiás e Aparecida de Goiânia. Assim, Senador Canedo, considerando a ferrovia como marco da Vila São Sebastião (antes denominada de Esplanada), já surgiu como distrito goianiense. Por isso, não se apaga o que não foi escrito.

O distrito de Senador Canedo (municipalizado pela lei $\mathrm{n}^{\circ} 10.435$ de 1988) funcionou como subúrbio de Goiânia por quatro décadas, sob péssimas condições de infraestrutura urbana, servindo no contexto metropolitano como local de assentamento do excedente humano de Goiânia.

A história socioespacial não escrita, assim dizendo, reside na dificuldade, e por que não dizer inexistência, de bibliografias e informações geo-históricas dos órgãos gestores (Estado e município de Goiânia). Os dados censitários do distrito só foram desagrupados pelo IBGE na década de 1970, o que nos faz defender a ideia de apêndice urbano goianiense com duas décadas sem informação sobre o distrito. Em segundo, as recentes fontes bibliográficas, todas datadas da década de 1990, narram aspectos sociohistóricos e espaciais de forma genérica e assim organizados: a) quando feitas por pessoas ligadas ao município, enfatizam o período de emancipação política com narrativa centrada na ideia de controle da produção socioespacial canedense; b) indicam o crescimento econômico da cidade no Estado de Goiás como panacéia dos problemas do município; c) camufla os reflexos coercitivos que o Estado e Goiânia conferiram socioespacialmente à Senador Canedo durante quatro décadas seguidas, especialmente em virtude dos programas de financiamento habitacional.

Quando a análise sobre o município parte de sujeitos provenientes da metrópole, três caminhos são seguidos pelos autores: a) utilizam dados secundários que não explica a lógica territorial da cidade, pois desconsideram os mecanismos legais - ainda que recentes - do município; b) são estudos de caso, relacionando a pressão demográfica de Goiânia em franjas urbanas da metrópole, e por isso mesmo não contemplam a espacialidade mais geral do município; c) interpretam, geralmente, que Senador Canedo é uma "cidade de segunda linha", cidade-dormitório, não explicando o porquê além de não admitir que a sua produção espacial tem dinâmica interna própria.

Alguns autores como Visconde (2002; 2007), Araújo (2008), Alves et al. (1996), Amaral (2000), Paixão (2001), Mendonça (2014), Soares (2014) são exemplos de estudos dessa vertente metodológica supracitada. Por sinal, narraram a produção e a lógica territorial de organização hegemônica de Goiânia no espaço canadense. Esses estudos, tendo em vista seus recortes socioespaciais, não versam sobre a dinâmica das quatro regiões de Senador Canedo, pois se relacionam mais com o contexto de desenvolvimento da cidade a partir da influência de Goiânia. Por outra perspectiva, o esforço teórico-empírico empreendido aqui ambiciona superar essa lacuna, a começar pela fragmentação territorial urbana de Senador Canedo, que é o pano de fundo da 
análise dos deslocamentos intraurbanos da cidade. Entender as distintas forças atuando em cada região administrativa de Senador Canedo é o foco seguinte.

\section{Senador Canedo: um espaço integrado}

Em nossa pesquisa, além da importância dada à dinâmica intraurbana, utilizaremos a proposta de zoneamento morfofuncional desenvolvida por Amorim Filho (2005). ${ }^{1}$ Esse autor, em sucessivos trabalhos de campo desde a década de 1970, desenvolveu um modelo de zoneamento a ser aplicado nos estudos das cidades pequenas, médias e grandes, que partiu de uma análise intraurbana enfatizando a forma e a organização dos espaços dessas cidades.

Levando em conta os marcos influenciadores da expansão urbana em Senador Canedo (Ferrovia, Estado e Petrobras) a produção urbana canedense vista a partir de fatores externos - verticalidade proposto por Santos (1994) torna-se mais complexa. A explicação morfológica funcional pauta-se também pelos fatores regionais e verticais que induziram a expansão urbana canedense no contexto metropolitano, considerando funções externas, como as de distribuição de combustíveis no centro oeste brasileiro. Para este caso específico, a autonomia financeira de Senador Canedo em virtude da instalação da Petrobrás foi um efeito colateral no processo de reestruturação urbana da RMG.

Focando a porção leste da RMG e a consequente expansão urbana canedense, numa perspectiva intrametropolitana, de acordo com o modelo de "núcleos múltiplos" de Amorim Filho (2005), Senador Canedo, em primeira instância desempenha o papel de "zona suburbana", fato evidenciado pelos trabalhos de Araújo (2008) e Visconde (2002; 2007) sobre dois lugares na metrópole. ${ }^{2}$

A outra razão se reside nos estudos da RMG que possuem uma escala de abordagem mais geral, não contemplando as especificidades de cada região administrativa de Senador Canedo. Essa premissa não anula a ideia de que pelo menos duas das quatro regiões administrativas de Senador Canedo (Galvão e Oliveiras) sejam, por um processo histórico, influenciadas diretamente pela segregação socioespacial de Goiânia. Esse fato indica que a estruturação fundiária da região leste de Goiânia implicou na fragmentação da porção oeste de Senador Canedo ocasionando duas regiões de conurbação. Por isso, a compreensão da produção do espaço em Senador Canedo não se restringe a essa cidade, mas também se estende à Goiânia ou vice-versa.

Em termos de localização, mobilidade e circulação Senador Canedo encontrase segregada socioespacialmente. Sendo assim, vale fazer uma ressalva importante em relação aos trabalhos de Araújo (2008), Visconde (2002; 2007) e Soares (2014) sobre a referida exclusão decorrente da ação do Estado. Se os fatores distância e localização foram essenciais na conclusão das análises sobre o fenômeno da segregação socioespacial em Senador Canedo, pela via intraurbana, nossa análise aponta para uma diferenciação

1. Amorim Filho (2005) assim desenvolve o modelo de zoneamento morfofuncional da estrutura urbana: área central, área pericentral, zona periférica e zona periurbana.

2. Amorim Filho (2005) utiliza o conceito de zona para a análise interna das cidades e região para a análise em redes, por exemplo. 
de segregação socioespacial em Senador Canedo, em que pese os fatores distância e localização e todos os custos demandados desses fatores.

A Região Oliveiras e Galvão são as mais integradas em termos de localização e infraestrutura. Isso nos leva a crer que a área mais afetada socioespacialmente pelo fator distancia é a Região Central, que, por sinal, já nasceu desligada da malha urbana metropolitana, originalmente desprovida de infraestrutura, e é a mais povoada e dependente de serviços de transporte coletivo. Contudo, nas duas últimas décadas, em decorrência de uma série de medidas tomadas pelo poder público e mercado imobiliário, a Região do Morumbi se tornou central na produção de espaços de lazer manifesta sob a forma de condomínios de chácaras, conforme Lima (2015).

Propondo uma análise do desenvolvimento intraurbano de Senador Canedo, conforme figura 03, tendo em vista a localização e a distância em relação à metropole, consideramos três padrões de integração sócioespacial diferentes: intermediária para a Região Central, alta para as Regiões do Jardim das Oliveiras e Vila Galvão, onde se situa o objeto de pesquisa de Araujo (2008), e altíssima integração da Região do Morumbi. Além disso, a justificativa do espaço integrado é qualificada, por exemplo, na qualidade e quantidade das vias de acesso e na centralidade fundiaria dos estoques rurais, conforme figura 03.

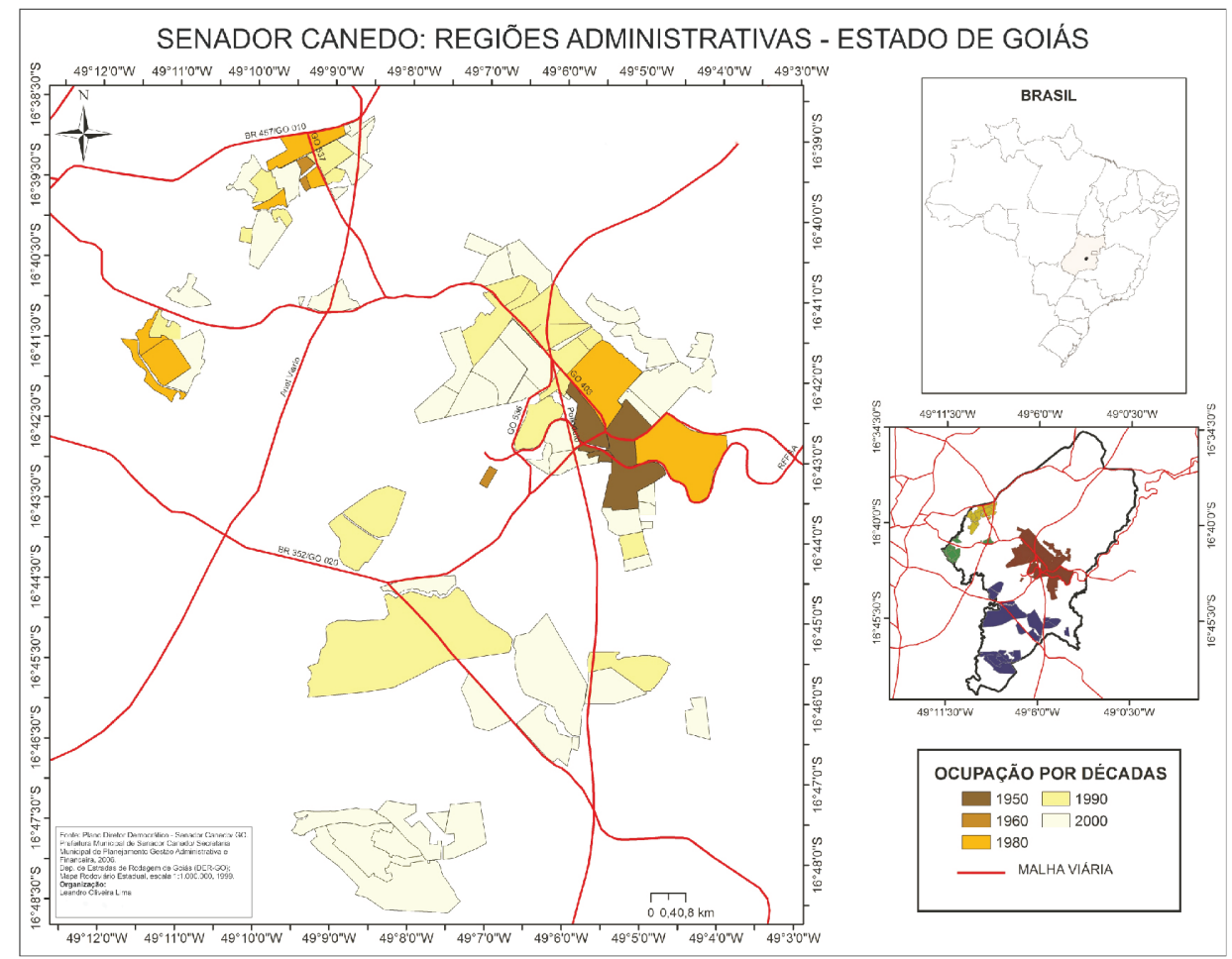

Figura 03: Senador Canedo: ocupação por décadas (1950-2000) 
A Região Central, com integração socioespacial intermediária existe um considerável número de conjuntos habitacionais oriundos das políticas de assentamento estadual. Em geral, as casas foram doadas, ou subsidiadas. No Conjunto Habitacional Jardim Sabiá (Região Central) as casas foram financiadas em 25 anos pela Caixa Econômica Federal. No Conjunto Uirapuru as casas são geminadas, construídas com material de menor qualidade e também foram financiadas.

O Conjunto Morada do Morro, construído pelos peemedebistas na década de 1990, possui um padrão inferior ao das casas do Valéria Perillo e dista mais de dez quilômetros da capital. Falta água diariamente e não receberam aquecedor solar. Mais recentemente houve a instalação dos Conjuntos Residenciais Dona Lindu e Conjunto Bougainville assentando mais de 300 famílias pela Agencia Goiana de Habitação (AGEHAB). Na Região Central, onde não predominou as políticas de assentamento direto, houve intervenção política na promoção de loteamentos de baixo custo cujas construções foram (e são) feitas pelo sistema autoconstrução que, pela lógica, demanda um grau maior de investimento do proprietário, como é o caso de setores como Jardim Todos os Santos, Jardim Canedo I, II e III e Setor Aracy Amaral.

As regiões Galvão e Oliveiras tem padrão alto padrão de integração socioespacial, como identificamos anteriormente (LIMA, 2014). Uma característica que nos leva a atribuir essa hierarquização são as áreas de conurbação limitadas por cursos d'agua. Encontram-se separadas pelo Rio Meia Ponte e afluentes. Tais acidentes são condicionantes naturais que impedem uma conurbação mais complexa com os muros dos condomínios fechados de Goiânia. Porém, essas regiões distam, em média, $8 \mathrm{~km}$ dos grandes equipamentos urbanos e do centro de Goiânia, o que corresponde menor tempo de acesso aos equipamentos da centralidade de Goiânia. Na década de 2000, em virtude da chegada das classes mais ricas de Goiânia à porção sudeste da cidade, outros equipamentos de grande porte, como a sede da prefeitura de Goiânia, O Centro Cultural Oscar Niemeyer, o Ginásio Internacional Goiânia Arena, o Autódromo de Goiânia, O Flamboyant, Carrefour, Wall Mart entre outros (CORRÊA, 2006), se concentraram na região, o que conferiu um maior valor econômico às áreas desta porção da RMG.

Vale dizer ainda que Senador Canedo possui distância relativa privilegiada em termos locacionais na RMG, se comparada, por exemplo, à Trindade e à Goianira. Além desses fatores, a região da Vila Galvão, que se localiza no limite da fronteira com Goiânia, é atendida por três linhas de ônibus, dista em média $5 \mathrm{~km}$ do Terminal do Novo Mundo em Goiânia, o que favorece rápido acesso aos hospitais, clínicas e ao centro de Goiânia.

Um ponto importante em relação ao favorecimento da região Galvão e que coloca a região do Jardim das Oliveiras em posição intermediária na escala de segregação é a maneira pelo qual se efetuou o assentamento. Segundo Visconde (2002; 2007), a articulação junto ao Estado foi feita pela Federação Goiana de Inquilinos e Posseiros (FEGIP) no sentido de pressionar o estado à doação de terras e não de construir casas. Além disso, a Região do Oliveiras, por sua localização, é menos privilegiada que a Região Vila Galvão. 


\section{Considerações finais}

A contribuição de Villaça (1998) na análise intraurbana das regiões metropolitanas permite uma compreensão da segregação socioespacial das metrópoles brasileiras, com os atores responsáveis pela estruturação espacial das cidades. Em Goiânia, cidade comparativamente bem mais recente do que aquelas analisadas pelo autor, há semelhanças nesse processo de produção urbana, como destaca Bernardes (2000), sobre as infrações do plano diretor, enquanto mecanismo de regulação do solo urbano em Goiânia, na década de 1950.

A produção do espaço metropolitano pela elite - regiões sul e sudeste de Goiânia - dominando equipamentos centrais e não centrais e atraindo-os para sua direção de deslocamento conferiu a Senador Canedo localização privilegiada no contexto metropolitano. O privilégio tornou-se ainda maior à região da Vila Galvão. Por outro lado, sabe-se que o privilégio locacional pouco contribui com as classes populares, já que a estrutura socioeconômica permanece rígida, limitando a mobilidade socioespacial dos citadinos.

Por mais parecidas que sejam as cidades em termos de processos espacial elas possuem características que lhes são específicas. Cada cidade tende a se constituir historicamente conservando o caráter orgânico da comunidade que nela vive. É assim que Senador Canedo, enquanto uma cidade da região metropolitana, possui problemas intraurbanos que não destoam da realidade goianiense, mas que possui especificidade própria, se comparada às demais cidades da RMG. Assim, o uso da escala intraurbana torna-se salutar para entendermos os fenômenos desencadeados em Senador Canedo os quais consideramos como parte de uma estruturação intraurbana da própria cidade. Partindo dela, buscamos alertar os atores reguladores-modeladores no sentido de que estes tracem uma estratégia de desenvolvimento intraurbano que melhor beneficie as classes sociais canedenses.

A escala na análise geográfica da cidade depende dos questionamentos que fazemos ao nosso objeto. Esse fato merece uma consideração relevante sobre a importância da análise micro e macro da realidade, que qualifica a produção científica. Para Revel et al. (1998), não devemos hierarquizar uma ou outra escala - a macro e a micro. Porém, em Geografia, a capacidade de explicação da variabilidade da paisagem qualifica a análise do fenômeno advém, também da escolha da escala geográfica.

Por isso mesmo, sem estabelecer um jogo de escalas, pois isso seria uma armadilha metodológica, segundo Gribaudi (1998), apontamos que a perspectiva do lugar - como micro escala de abordagem na Geografia - não torna evidente o arranjo espacial de Senador Canedo. Nesse sentido, é preciso vincular "o morar distante" aos atributos do espaço, considerando que o acesso aos benefícios do modo de vida urbano deve ir além das condições físicas das moradias sejam as autoconstruídas ou mesmo aquelas ofertadas pelo governo. E é exatamente nessa relação que a escala intraurbana é essencial aos estudos urbanos. 


\section{Referências}

ALVES, A. P. S. et al. A História do Espaço Agrário de Senador Canedo como Município Goiano. Paper. UFG: Goiânia, 1996.

AMARAL, E. F. L. Mobilidade Sócio-Espacial na Região Metropolitana de Goiânia: o caso de Senador Canedo 2000. 45 f. Projeto de Pesquisa. Faculdade de Ciências Humanas e Filosofia, Universidade Federal de Goiás, 2000.

AMORIM FILHO, O. B.; FILHO, N. S. A Morfologia das Cidades Médias. Goiânia: Vieira, 2005.

ANJOS, A. F. Dinâmica intraurbana e espaço metropolitano: um estudo sobre o município de Goianira-Go. 2009. Dissertação (Mestrado em Geografia) Instituto de Ciências Sócio-Ambientais, Universidade Federal de Goiás, Goiânia, 2009.

ARAÚJO, M. J. R. A produção de um novo lugar na região metropolitana de Goiânia: o Conjunto Habitacional Valéria Perillo em Senador Canedo, GO. 2008. Dissertação (Mestrado em Geografia) - Instituto de Estudos Sócio-Ambientais, Universidade Federal de Goiás, Goiânia, 2008.

ARRAIS, T. A. Acionando territórios: breves reflexões sobre a mobilidade na região metropolitana de Goiânia; 2006. Disponível em: <http://www.observatoriogeogoias .com.br/>. Acesso em: 10 out. 2014.

. A escala de análise metropolitana em questão: considerações sobre o processo de metropolização. Revista do Departamento de Geografia - USP, São Paulo, v. 24, 2012.

. Morar na metrópole, viver na praia ou no campo: a segunda residencia e o mercado imobiliário metropolitano. Goiânia: EdUFG, 2013.

BARBOSA, A S. NETO, A. T., GOMES, H. Geografia: Goiás-Tocantins. Goiânia: EdUFG, 2004.

BERNARDES, G. D. Considerações sobre o plano de Goiânia. In: SILVA, L. S. D. (Org.). Relações Cidade-Campo: fronteiras. Goiânia: UFG, 2000, p. 155-180.

CAVALCANTI, L. de S. Uma geografia da cidade: elementos da produção do espaço urbano. In: . (Org.). Geografia da cidade: a produção do espaço urbano de Goiânia. Goiânia: Alternativa, 2001.

. Cidade e vida urbana: a dinâmica do/no espaço intra-urbano e a formação para

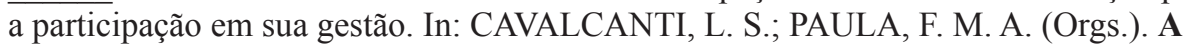
cidade e seus lugares. Goiânia: Vieira, 2007, p. 10-28.

. Lugares Periféricos da Cidade, Vida Cotidiana e o Ensino de Geografia.

In:__. Geografia Escolar e a Cidade: ensaios sobre o ensino de Geografia para a vida urbana cotidiana. São Paulo: Papirus, 2008.

CLARK, D. Introdução à Geografia Urbana. Rio de Janeiro: Bertrand Brasil, 1991. 
CORRÊA, E. A. L. Descentralização e formação de novas centralidades

em Goiânia: o caso do Setor Jardim Goiás. 2006. 92. f. Monografia - Unidade Universitária de Ciências Econômicas e Humanas, Universidade Estadual de Goiás, Anápolis, 2006.

COSTA, F. A. G. Informações Socioeconômicas Municipais de Senador Canedo. Goiânia: SEBRAE/GO, 1997.

GOMES, R. R. Goiânia Desigual e Segregadora. In: CAVALCANTI, L. S.; PAULA, F. M. A. (Orgs.). A cidade e seus lugares. Goiânia: Vieira, 2007, p. 29-52.

GRIBAUDI, M. Escala, pertinência, configuração. In: REVEL, J. (Org.). Jogo de Escalas: a experiência da microanálise. Rio de Janeiro: Ed. Fund. Getúlio Vargas, 1998, p. 121-150.

LIMA, O. L. Reestruturação intra-urbana em Senador Canedo: a implantação do shopping Senador Center e os impactos socioespaciais ocorridos na Av. Dom Emanuel. 2007. 122. f. Monografia - Unidade Universitária de Ciências Econômicas e Humanas, Universidade Estadual de Goiás, Anápolis, 2007.

. Metropolização e Mercado Imobiliário: a produção do espaço dos condomínios de chácaras da RMG. Tese de Doutorado. Goiânia: IESA, UFG, 2014.

MENDONÇA, G. H. O bairro Jardim das Oliveiras enquanto uma centralidade de Senador Canedo (GO). 66. f. Monografia - Unidade Universitária de Ciências Econômicas e Humanas, Universidade Estadual de Goiás, Anápolis, 2014.

MORAES, L. R. Retrospectiva Histórica de Senador Canedo: das origens à emancipação política. Senador Canedo: 2000. Mimeografado.

PAIXÃO, G. L. R. A expansão urbana de Senador Canedo. Monografia (Licenciatura em Geografia). - Unidade Universitária de Ciência Sócio Econômicas e Humanas, Universidade Estadual de Goiás, Anápolis, 2001.

PAULA, F. M. de A. Descentralização e segregação sócio-espacial em Goiânia: uma análise das centralidades dos setores Bueno, Oeste e Marista. 2003. Dissertação (Mestrado em Geografia) Instituto de Ciências Sócio-Ambientais, Universidade Federal de Goiás, Goiânia, 2003.

PINTO, J. V. C. O espaço intraurbano de Aparecida de Goiânia: centralidades na metrópole Goiana. 2009. Dissertação (Mestrado em Geografia) Instituto de Ciências Sócio-Ambientais, Universidade Federal de Goiás, Goiânia, 2009.

. Cidade de limiar: notas teórico-metodológicas acerca do caráter político dos arrabaldes metropolitanos brasileiros. Revista Formação. Vol. 01. n. 21. 2014.

REVEL, J. (Org.). Jogo de Escalas: a experiência da microanálise. Rio de Janeiro: Ed. Fund. Getúlio Vargas, 1998.

SANTOS, M. A Natureza do Espaço. São Paulo: Edusp, 1994. 
SOARES, P. H. S. Segregação socioespacial no Residencial Flor do Ipê I em Senador Canedo-GO. 2014. Monografia. Instituto de Ciências Sócio-Ambientais, Universidade Federal de Goiás, Goiânia, 2014.

SOUZA, M. L. de. O Desafio Metropolitano: um estudo sobre a problemática sócioespacial nas metrópoles brasileiras. Rio de Janeiro: Bertrand Brasil, 2000.

. Fobópole: o medo generalizado e a militarização da questão urbana. Rio de Janeiro: Bertrand Brasil, 2008, p. 51-91.

SPÓSITO, M. E. B. A Gestão do Território e as diferentes escalas da centralidade urbana. In: Revista TERRITÓRIO, ano III, nº. 4, 27-53 jan./jun. 1998. 2007. . (Org.). Cidades Médias: espaços em transição. São Paulo: Expressão Popular,

VILLAÇA, F. Espaço intra-urbano no Brasil. São Paulo: Studio Nobel: FAPESP: Lincoln Institute, 1998.

VISCONDE, M. S. X. Um lugar na metrópole: o bairro Jardim das Oliveiras no município de Senador Canedo (GO). 2002. Dissertação (Mestrado em Geografia) Instituto de Estudos Sócio-Ambientais, Universidade Federal de Goiás, Goiânia, 2002. . Jardim das Oliveiras: um espaço segregado da metrópole. In: CAVALCANTI, L. S.; PAULA, F. M. A. (Orgs.). A cidade e seus lugares. Goiânia. Vieira, 2007, p. 160-174.

\section{Outras fontes:}

LEI 176, Goiânia, 16 de Março de 1950.

LEI 239, Goiânia, 31 de Março de 1953.

LEI Estadual 10.435, Goiás, 09 de Janeiro de 1988.

Leandro Oliveira Lima

Possui doutorado e mestrado em Geografia pela Universidade Federal de Goiás e graduação em Geografia pela Universidade Estadual de Goiás. Atualmente é professor efetivo da UEG - Campus Goiás.

Avenida Deusdeth Ferreira, setor central. Cep: 74000-000. Goiás-GO, Brasil.

E-mail: leandro_oliveira_lima@hotmail.com 